\title{
Numerical approaches for the analysis of timber frame walls Elisa Poletti ${ }^{1, a}$, Graça Vasconcelos ${ }^{1, b}$, Paulo B. Lourenço ${ }^{1, c}$ and Maria Pia
}

\author{
${ }^{1}$ Institute for Sustainability and Innovation in Structural Engineering (ISISE) \\ University of Minho, Guimarães, Portugal

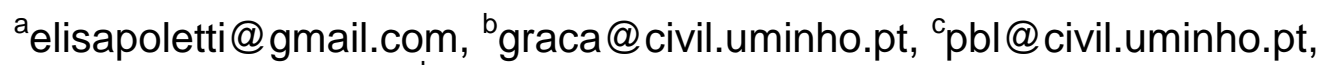 \\ dmariapiaciocci@gmail.com
}

Keywords: timber frame, traditional connections, numerical analysis, calibration, parametric analysis

\section{Introduction}

Numerical modelling is an important tool for the analysis of the behaviour of structural elements when appropriately validated on experimental results and can be used to predict the response of a structure after interventions are made. A number of numerical studies analysing the seismic performance of modern timber frame shear walls exist, while only recently the attention has focused on traditional timber frame walls, which represent an important historic seismic-resistant construction typology, particularly in Mediterranean countries.

Timber frame walls have proven to be effective when subjected to seismic loads, as testified by real case studies [1] and by experimental observations $[2,3,4,5]$. The origin and diffusion of these structures has been thoroughly described in these works and it will not be discussed here. Nevertheless, the numerical tool would allow to complement these findings and help in the preservation of existing structures.

Different approaches can be taken when modelling this type of elements, varying from complicated 3D modelling, accurately representing connections, pegs and nails, to simplified 2D modelling, adopting linear and springs elements to represent timber members and joints.

Kouris and Kappos [6] performed non-linear numerical analyses on traditional half-timbered walls. Based on the test results of Santos [7], the authors first performed a detailed 2-D modelling of a wall, adopting plane-stress elements and considering non-linear orthotropic properties for wood, while the contacts in timber elements was simulated adopting interface elements. Infill was not included in the model. The model was able to appropriately simulate experimental results, being able to capture the gradual softening of the walls as well as their capacity. To be able to model whole buildings in a simplified way, the authors created a simplified model using beam and link elements, while non-linear axial hinges were used for the diagonals. The application of this model to a building façade proved to be satisfactory. The model was later expanded to take into consideration masonry infill by adopting a plasticity model for masonry and it can provide predictions of local quantities such as penetration of elements and relative sliding [8].

Quinn and D'Ayala [9] modelled traditional Peruvian timber frame walls (quincha) using 2-D beam elements and adopting semi-rigid spring elements to model the mortise and tenon connections of the wall. The springs were calibrated based on experimental results and using the components method and the preliminary results appear to be reasonably good.

Another approach to the modelling of timber frame walls is the use of analytical hysteretic models calibrated on experimental results to a simplified numerical wall model. Ceccotti and Sandhaas [10] 
performed such an analysis on a traditional timber frame wall creating a numerical model consisting of lumped masses and rotational springs, where the rigid elements represent the timber elements, while the global cyclic behaviour of the wall is given only by the springs. The springs could model both rotations and vertical uplifting. This model was then extended to model a whole building. A similar approach was used by Meireles [11] introducing an analytical hysteretic model calibrated on experimental results in the finite element software, modelling a traditional Pombalino wall representing the connections by means of spring elements. A macro-element was developed to represent the Portuguese frontal walls inside a masonry building. The hysteretic model was also implemented in an existing finite element model for timber frame structures [8] providing acceptable results. Hicyilmaz et al. [12] developed a numerical model of a dhajji dewari building, taking into account parameters such as vertical load, shortening of the diagonal bracings and removal of nails from the wall.

Numerical models are available even for traditional timber connections. Hong and Barrett [13] developed a 3-D finite element model for Japanese post and beam connections (basically a mortise and tenon joint), modelling the nails and steel plates of the connection and the crushing of timber that occurred at the mortise-tenon interface. Branco et al. [14] modelled the behaviour of traditional timber roof connections using nonlinear moment-rotation laws and hysteretic rules in order to represent the cyclic response of the joint. Considering modern connections, Tannert et al. [15] studied the strength prediction of rounded dovetail connections considering size effects.

In this paper, two distinct numerical models have been validated to simulate the mechanical behaviour observed in the experimental results of cyclic tests on traditional timber frame walls. A parametric study is then presented considering some variables such as post continuity, type of infill and wall geometry.

\section{Brief overview of experimental observations}

To study the seismic response of traditional Portuguese timber frame walls, quasi-static in-plane cyclic tests were performed on real scale specimens [2]. Half lap joints were used for the connections between the elements of the main frame, while the diagonals were simply nailed to the frame (Fig 1). In general the walls showed a good capacity and ductility. Results greatly varied depending on the level of vertical pre-compression and on the presence of infill, which could alter the response of the wall from a shear one to a flexural one (Fig 1). Damages were concentrated at the connections and uplifting of the non-continuous lower connections was severe particularly for infill walls. For a full description of the experimental results, see [2].
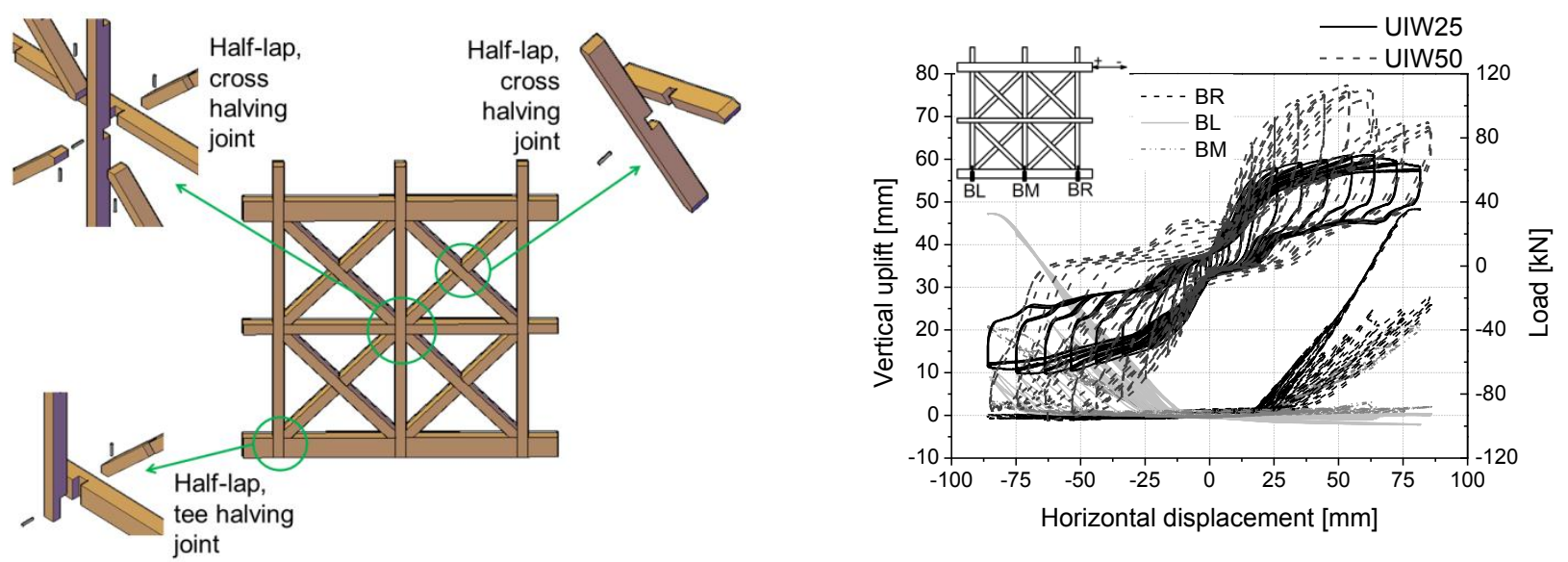

Fig. 1 Wall geometry (left) and flexural behaviour of timber frame wall with infill (right) [2]

\section{Numerical modelling of walls}

In order to simulate numerically the results obtained experimentally, the walls were modelled adopting 2-D finite elements, specifically plane stress elements and beam elements. The models were calibrated based on the experimental envelope curves. 
2-D model with plane stress elements. A first model of the wall was created adopting plane stress elements and interface elements for the connections using the finite element code DIANA [16]. The elements used for timber were eight-node quadrilateral isoparametric plane stress element CQ16M, whereas the interfaces used were line based elements CL12I with $3+3$ nodes.

To take into account the uplift observed during the experimental tests [2], interface elements were introduced between the posts and the bottom beam. The horizontal interface elements should simulate the bottom half-lap joint. Moreover, interface elements were introduced between the diagonals and the main frame to represent the nailed connections between the two elements (Fig. 2). These connections were crucial during the experimental tests, particularly when infill is not present, as they would penetrate the main frame. Moreover, using a rigid connection would have stiffened the wall in an unrealistic way.

Note that, to simplify the calibration of the model, it was assumed that the half-lap connections of the diagonals and of the middle and top beam of the wall were rigid. To simulate the crushing observed in these connections, mainly at the central post, different materials properties were considered in this region. Infill was modelled adopting six-node triangular isoparametric plane stress elements (CT12M). Masonry infill was assumed as a continuous and isotropic material and the brick joints were not represented. Interface elements (CL12I) were introduced between the masonry infill and the timber frame to represent the connectivity between the two materials. Boundary conditions and loading protocols adopted reproduced the ones adopted during the experimental tests [2]; note that two vertical load levels were considered, namely $25 \mathrm{kN} /$ post and $50 \mathrm{kN} /$ post. The solution algorithm used for the non-linear analyses performed was the full NewtonRaphson method and the convergence criterion was energy based.
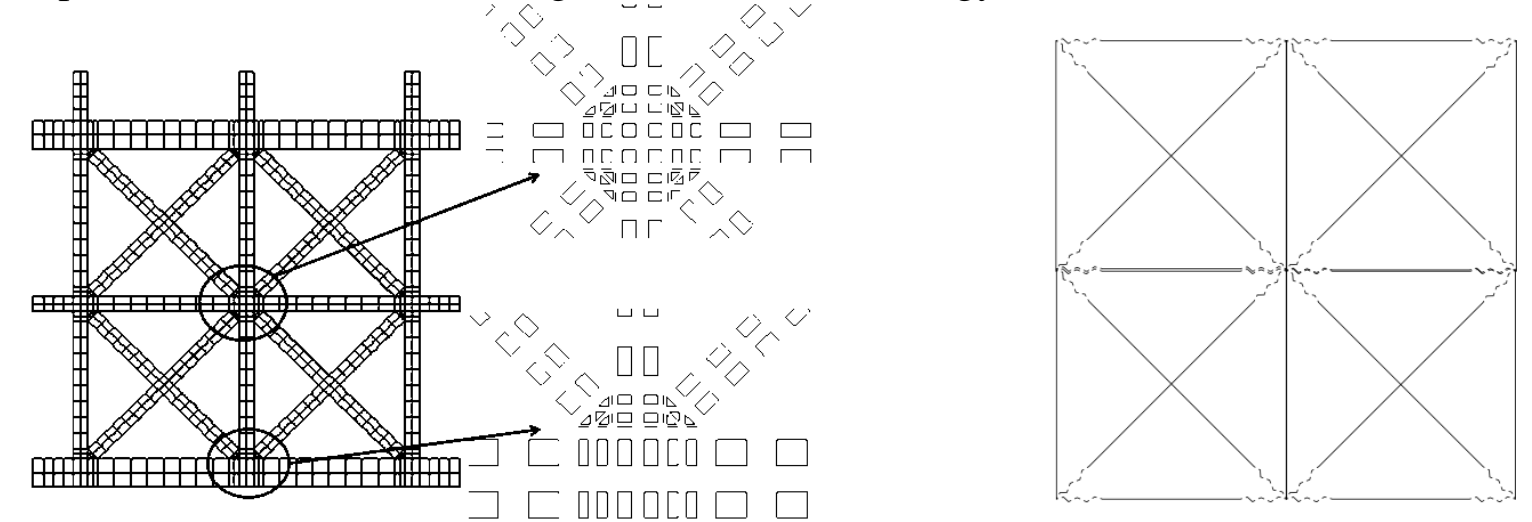

Fig. 2 Model geometry: plane stress elements (left) and beam elements (right).

Non-linear properties were assumed for timber and for the timber-to-timber and infill-to-timber interfaces. The orthotropic behaviour of timber is taken into account by using the Rankine-Hill Anisotropic model available in DIANA [16]. In order to model the anisotropic behaviour of the material, the model considers a Hill yield criterion in compression and a Rankine yield criterion in tension. For interface elements, a Coulomb Friction model was used, combining the friction criterion with a gap criterion, in order to allow the detachment of the diagonals, and assuming a Mode-II constant shear retention model after gap appearance [17]. The material properties were obtained from the results of the material characterization carried out in [2]. The additional information necessary was obtained using the JCSS probabilistic model code [18], see Table 1. For the half-lap joints which were not directly modelled, timber properties were reduced by $40 \%$. For interface elements representing the bottom connections, a normal stiffness of $1,25 \mathrm{~N} / \mathrm{mm}^{3}$ was assumed, while tangential stiffness was $5 \mathrm{~N} / \mathrm{mm}^{3}$. For the interfaces at the diagonals, a lower cohesion and friction angle were assumed in relation to half-lap joints, since no interlocking was present. Normal and tangential stiffness were both assumed as $1 \mathrm{~N} / \mathrm{mm}^{3}$. Infill properties were obtained by [2], while infill-to-timber interfaces were assumed as weak, with a normal and tangential stiffness of 1 and $0,5 \mathrm{~N} / \mathrm{mm}^{3}$ respectively. 
Table 1 Material properties used for timber [18]

\begin{tabular}{|c|c|c|c|c|c|c|c|c|}
\hline $\mathbf{f}_{t, 0}$ & 25 & $\mathrm{MPa}$ & $\mathbf{G}_{\mathbf{v}}$ & 700 & $\mathrm{MPa}$ & $\gamma$ & 9 & - \\
\hline$f_{t, 90}$ & 9 & $\mathrm{MPa}$ & $v$ & 0.3 & & $\mathbf{G}_{\mathrm{ft}, \mathbf{0}}$ & 70 & $\mathrm{Nmm} / \mathrm{mm}^{2}$ \\
\hline $\mathbf{E}_{\mathbf{0}}$ & 11000 & $\mathrm{MPa}$ & $\rho$ & 590 & $\mathrm{~kg} / \mathrm{m}^{3}$ & $\mathbf{G}_{\mathrm{ft}, \mathbf{9 0}}$ & 50 & $\mathrm{Nmm} / \mathrm{mm}^{2}$ \\
\hline $\mathbf{E}_{90}$ & 900 & $\mathrm{MPa}$ & $\alpha_{\tau}$ & 1 & - & $\mathbf{G}_{\mathrm{fc}, \mathbf{0}}$ & 130 & $\mathrm{Nmm} / \mathrm{mm}^{2}$ \\
\hline $\mathbf{f}_{\mathrm{c}, \mathbf{0}}$ & 35 & $\mathrm{MPa}$ & $\alpha_{h}$ & 1 & - & $\mathbf{G}_{\mathrm{fc}, 90}$ & 70 & $\mathrm{Nmm} / \mathrm{mm}^{2}$ \\
\hline $\mathbf{f}_{c, 90}$ & 5 & $\mathrm{MPa}$ & $\beta$ & -1 & - & $\kappa_{\mathrm{p}}$ & 0.001 & - \\
\hline
\end{tabular}

$v$ is Poisson's ratio; $G_{v}$ is the shear modulus; $\gamma$ is the material density; $E_{0}$ and $E_{90}$ are the moduli of elasticity parallel and perpendicular to the grain; $\mathrm{f}_{\mathrm{c}, 0}, \mathrm{f}_{\mathrm{c}, 90}, \mathrm{f}_{\mathrm{t}, 0}$ and $\mathrm{f}_{\mathrm{t}, 90}$ are the compressive and tensile strength parallel and perpendicular to the grain; $\mathrm{G}_{\mathrm{fc}, 0} ; \mathrm{G}_{\mathrm{fc}, 90} ; \mathrm{G}_{\mathrm{ft}, 0} ; \mathrm{G}_{\mathrm{ft}, 90}$ are the corresponding fracture energies in compression and tension parallel and perpendicular to the grain; $\alpha_{\tau}$ is a factor that determines the shear stress contribution to tensile failure; $\alpha_{h}$, is a factor that relates the equivalent length of the element to the area of the finite element; factor $\beta$ couples the normal compressive stresses; factor $\gamma$ controls shear stress contribution to compressive failure,; $\kappa_{\mathrm{p}}$ is the equivalent plastic strain corresponding to the peak compressive stress.

Assuming such values of material properties, the numerical model was calibrated based on experimental results with no infill material; results were compared to the envelope curves obtained from the experimental quasi-static in plane cyclic tests. It is observed that a reasonable fitting between experimental and numerical results was obtained both in terms of stiffness, lateral resistance and maximum displacement (Fig. 3). In terms of initial stiffness, the numerical model exhibits a value of $3.8 \mathrm{kN} / \mathrm{mm}$ for both load levels, which is in good accordance with the experimental results for the higher vertical load, with an increase of only $6 \%$. For the lower vertical load the error is higher, with an increase of stiffness of approximately $45 \%$. In terms of maximum load, both load levels exhibited a good approximation, with a decrease of $9 \%$ and $15 \%$ respectively for the lower and higher vertical load [17]. In terms of deformation patterns and damages, the uplift of the lateral connection for the lower vertical load level reached $65 \mathrm{~mm}$, a value comparable with what observed experimentally. In terms of stresses distribution, the models presented important stress concentrations at the central joints, with detachment of the diagonals, replicating what was observed experimentally. Similarly, a good approximation was obtained for the model with infill.
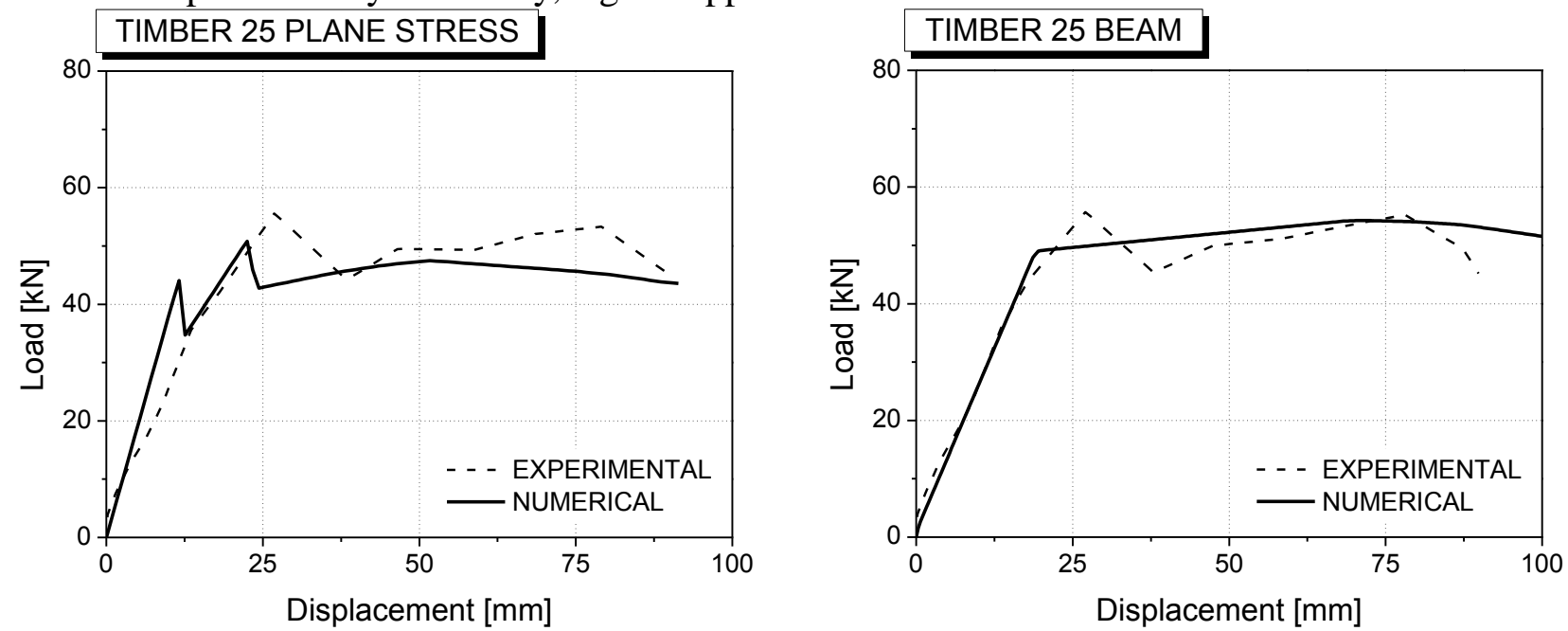

Fig. 3 Model calibration: plane stress elements (left) and beam elements (right) model results

2-D model with beam elements. Considering that the plane stress model still presents some complications, particularly in terms of material properties, since non-linearities are assumed for all elements, and having as a goal the modelling of a whole structure, for which such a model would be computationally expensive, a simplified 2-D model was created using beam elements on the finite element software SAP2000 [19]. Replicating the real geometry of the walls (Fig. 1), each timber element of the main frame was modelled using a frame element with a linear behaviour. No infill was considered and the linear elastic timber properties of Table 1 were assumed for this model. All non-linearities were concentrated in the semi-rigid connections that were modelled using link 
elements with multi-linear elasticity property. Each link element was assumed to be composed of six separate springs, one for each deformational degree of freedom. In particular, two link elements were considered: link 1 and link 2; link 1 was located at each nailed connection between the main frame and the diagonal elements, while link 2 at each half-lap connection between the elements of the main frame. Because of the planar nature of the problem, only the axial $\mathrm{u} 1$, shear $\mathrm{u} 2$ and rotational $\mathrm{r} 3$ stiffness were considered for the element deformational DOFs. While the axial and the shear stiffness were specified for link 1, the rotational one was defined for link 2. Non-linear forcedeformation relationships were used for all link elements (Fig.4) [20]. For link 2, a tri-linear behaviour was assumed based on in-plane cyclic tests carried out on the half-lap connections of the wall [21]. In particular, the mean values of the initial and the final rotational stiffness were calculated as $\mathrm{k}_{\mathrm{in}}=171 \mathrm{kNm} / \mathrm{rad}$ and $\mathrm{k}_{\mathrm{fin}}=47 \mathrm{kNm} / \mathrm{rad}$, respectively. For link 1 , after reaching the maximum capacity, the load progressively decreased until a null value until the ultimate displacement . The value of $10000 \mathrm{kN} / \mathrm{m}$ obtained by applying the inverse fitting method in the elastic analysis was assumed as the initial stiffness of the axial and shear stiffness. The capacity of the connection was calculated by considering the compressive strength perpendicular to the grain and the contact areas with the presence of initial clearances. The ultimate displacement was assumed to be the same of that of half-lap connections: when the failure occurred for the half-lap connection, the connection between the diagonal and the main frame no longer worked [20].

Link1

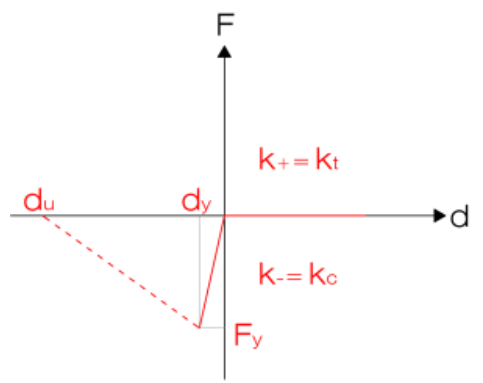

(u1)

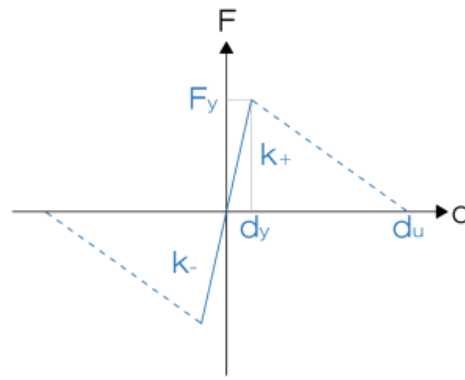

(u2)
Link2

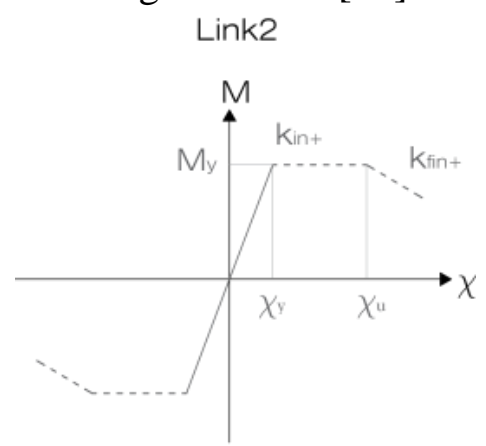

$\left(r_{3}\right)$

Fig. 4 Force-displacement and moment-curvature relationships assumed for link [20].

Comparing the numerical results thus obtained with the experimental envelope curve of the cyclic tests performed on timber frame walls [2] (Fig. 3), a good approximation was obtained with this simplified model. The consideration of all the connections of the wall and the calibration of the model with the inverse fitting method allowed for a better prediction of the stiffness of the wall. Moreover, the capacity and softening response of the timber frame wall were satisfactory predicted.

Parametric analyses. Parametric analyses were performed for the first model in order to better understand the influence of different parameters on the lateral response of the wall. In fact, parametric analyses are an important tool in numerical modelling since they allow to study the influence of different parameters on a calibrated model, a feat which would otherwise require extensive experimental testing.

During the experimental campaign [2], the partially rocking response of the walls was caused by the uplifting of the bottom joints, due to the fact that the half-lap was not complete. To better capture the importance of post continuity, the normal stiffness of the interface elements linking the bottom beam to the posts was varied, considering values ranging from $25 \%$ to $500 \%$ of the calibrated value. The tangential stiffness was kept constant, as it does not influence the uplifting of the post.

Both initial stiffness and maximum load are influenced by the post continuity. For an increase of normal stiffness $\mathrm{k}_{\mathrm{n}}$ higher than $500 \%$ the parameter loses its influence, as the connection becomes rigid (Fig. 5). For high normal stiffness values, the tensile stresses in the joints of the central beam reached the maximum tensile strength value assumed for those elements, as the response of the wall 
was predominantly in shear. In terms of initial stiffness $K_{i n}$, it increases with increasing values of normal stiffness of the connection until a constant value is reached, after which other parameters, such as timber strength and connection to the diagonals should have more relevance [17].
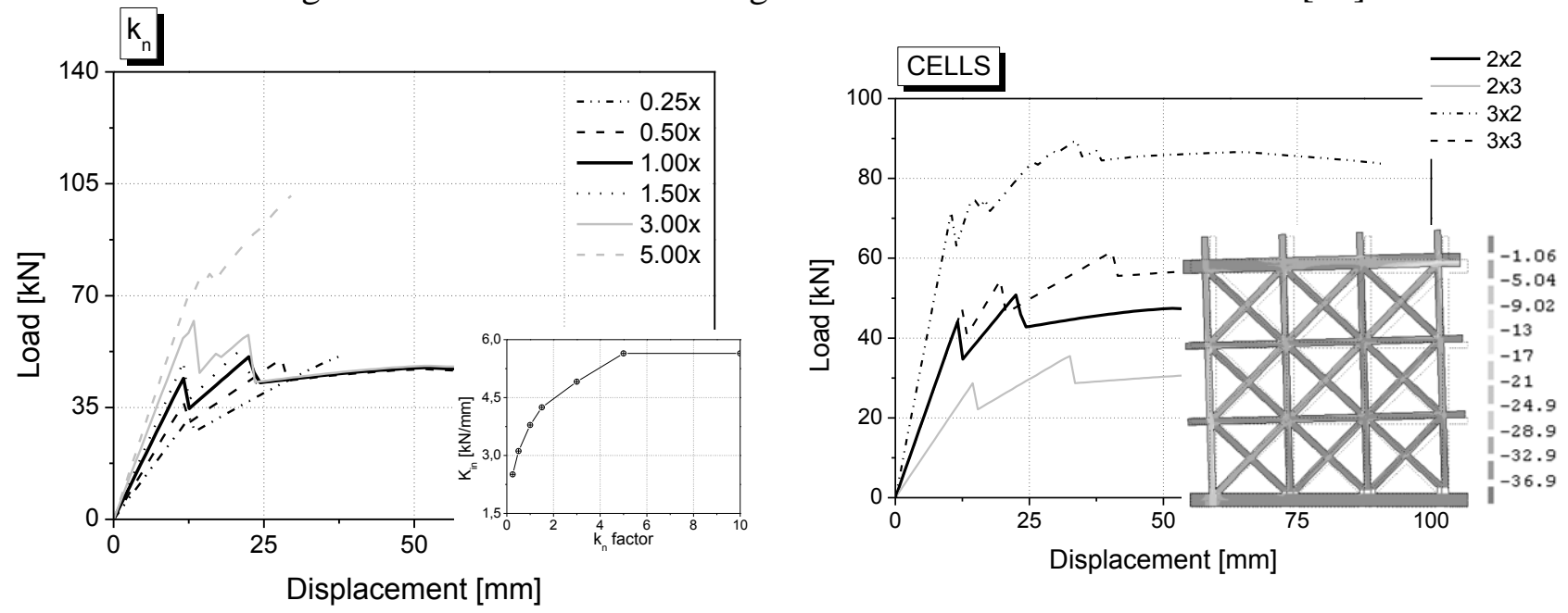

Fig. 5 Parametric analyses: influence of post continuity (left) and of length-to-height ratio (right)

Other parameters influencing the behaviour of the wall are represented by material properties, namely timber and infill properties. These properties influence mainly the capacity and the post peak behaviour of the wall, while timber-to-timber and infill-to-timber connection properties affect the stiffness of the wall [17]. These results were also observed during the analysis performed with the simplified beam model [20].

Another parameter to be taken into consideration is the wall geometry. Timber frame walls have a great variability in terms of geometry, namely height to length ratio of the wall, height to length ratio of a single cell, sectional dimensions of timber elements, positioning of diagonals. In this study, only the first issue will be discussed, keeping as a future development the analysis of the other parameters. Three wall geometries were analysed, namely a wall with three cells along the length and two cells along the height $(3 \times 2)$, a wall with two cells along the length and three cells along the height $(2 \times 3)$ and a wall with three cells both along the length and along the height $(3 \times 3)$. The general behaviour of the models in terms of stress paths and deformation was similar to what observed for the original model ( $2 \times 2$ configuration) (Fig. 5), with similar stresses concentrations in the connections and at the compressed post. The response of the walls changed in terms of initial stiffness and load capacity (Fig. 5). For the same height, a higher width of the wall, corresponding to a lower height to length ratio, leads to higher initial stiffness and load capacity. For example, model $3 \times 2$ has an initial stiffness $80 \%$ higher than that of model $2 \times 2$, while model $3 \times 3$ has an increase of $92 \%$ on the stiffness when compared to model $2 \times 3$. In terms of maximum load, the increase is of $76 \%$ for two cells in height and of $98 \%$ for three cells in height. On the contrary, for the same width, a higher height (i.e. an higher height to length ratio) leads to smaller values of initial stiffness and load capacity, as the higher slenderness of the wall leads to a lower resistance.

\section{Further developments}

The numerical analyses carried out in this work are only a small part of what could be analysed when studying traditional timber frame walls. Among the future developments that could be mentioned, the most interesting ones are: (1) the implementation of a hysteretic model derived from the available experimental results [17]; (2) the simulation of the seismic behaviour of a whole timber frame structures through the execution of pushover and dynamic analyses on a simplified model. Additionally, the beam model can be modified in order to capture the rocking response of the wall, as in its current state the bottom connections cannot uplift. Other studies that could be considered are the assumption of different types of timber frame walls, with different geometries, configurations and materials than the Portuguese ones assumed in this study. 


\section{Conclusions}

In order to numerically represent a traditional timber frame wall, two 2-D models were created taking into account material and connection non-linearities, one adopting plane stress elements and one beam elements. Both models were calibrated on experimental results. For the plane stress model, a good correlation was found between the experimental results and the calibrated numerical model, for both timber frame and infill walls. Material non-linearity was considered for both timber and masonry as well as for timber-to-timber and timber-to-masonry interfaces.

The beam model was able to capture more accurately the stiffness of the wall, thanks to a more complete representation of the wall connections. The capacity was overpredicted and further parametric studies are necessary for this model.

From the parametric analyses it was observed that the greater influence on the behaviour of the wall is given by the continuity of the post as well as the connectivity between timber and masonry. This seems in accordance with experimental results as the response of the wall was governed by its connections. Additionally, the geometry of the wall influences its stiffness and load capacity, as a higher height to length ratio led to lower values of these parameters.

\section{References}

[1] Tsakanika-Theohari E., Mouzakis H., 2010, A post-Byzantine mansion in Athens. Restoration project of the timber structural elements, In Proceedings of WCTE World Conference on Timber Engineering, June 20-24, 2010 Riva Del Garda, Trento, Italy

[2] Poletti E., Vasconcelos G., 2015, Seismic behaviour of traditional timber frame walls: experimental results on unreinforced walls, Bulletin of Earthquake Engineering, 13: 885-916.

[3] Ruggieri N., Tampone G., Zinno R., In-plane vs Out-of-plane "Behaviour" of an Italian Timber Framed System: the Borbone Constructive System. Historical Analysis and Experimental Evaluation, International Journal of Architectural Heritage, doi: 10.1080/15583058.2015.1041189

[4] Vieux-Champagne F., Sieffert Y., Grange S., Polastri A., Ceccoti A., Daudeville L., 2014, Experimental analysis of seismic resistance of timber-framed structures with stones and earth infill, Engineering Structures 69,: 102-115.

[5] Dutu A., Sakata H., Yamazaki Y., Shindo T, 2015, In-Plane Behavior of Timber Frames with Masonry Infills under Static Cyclic Loading, Journal of Structral Engineering, 10.1061/(ASCE)ST.1943-541X.0001405, 04015140.

[6] Kouris L., Kappos A.J., 2012, Detailed and simplified non-linear models for timber-framed masonry structures, Journal of Cultural Heritage, 13(1): 47-58

[7] Santos S., 1997, Tests of Pombalino walls (in Portuguese), Nota Técnica N ${ }^{\circ}$ 15/97-NCE, LNEC, Lisbon

[8] Kouris L. A. S., Meireles H., Bento R., Kappos A.J., 2014, Simple and complex modelling of timber-framed masonry walls in Pombalino buildings, Bulletin of Earthquake Engineering, 12: $1777-1803$

[9] Quinn N., D'Ayala D., 2013. Assessment of the realistic stiffness and capacity of the connections in quincha frames to develop numerical models, Advanced Materials Research, 778: 526-533 
[10] Ceccotti A., Sandhaas C., 2010, A proposal for a standard procedure procedure to establish the seismic behaviour factor q of timber buildings, In Proceedings of WCTE World Conference on Timber Engineering, June 20-24, 2010 Riva Del Garda, Trento, Italy

[11] Meireles H., Bento R., Cattari S., Lagomarsino S., 2012, A hysteretic model for "frontal" walls in Pombalino buildings, Bulletin of Earthquake Engineering, 10(5): 1481-1502

[12] Hicyilmaz K.M.O., Wilcock T., Izatt C., da Silva J., Langenbach R., 2012, Seismic Performance of Dhajji Dewari, In: Proceedings of the 15th World Conference on Earthquake Engineering (15WCEE), 24-28 September, Lisbon

[13] Hong J.P., Barrett D., 2008, Three-dimensional finite solid element model for Japanese post and beam connection, In Proceeding of 10th World Conference on Timber Engineering (WCTE), 25 June, Miyazaki, Japan

[14] Branco J., Cruz P., Piazza M., Varum H., 2006, Modelling of timber joints in traditional structures, In Proceedings of International Workshop on "Earthquake Engineering on Timber Structures", Coimbra, Portugal

[15] Tannert T., Lam F., Vallée T., 2010, Strength Prediction for Rounded Dovetail Connections Considering Size Effects, Journal of Engineering Mechanics, 136(3): 358-366

[16] DIANA 2009, Diana Finite Element Code, Version 9.4.3. TNO Building and Construction Research, The Netherlands

[17] Poletti E. 2013, Characterization of the seismic behaviour of traditional timber frame walls, PhD Thesis, University of Minho, Guimarães, Portugal.

[18] JCSS 2006, Joint Committee on Structural Safety (JCSS) probabilistic model code - Part 3: Resistance models - 3.5 Properties of Timber

[19] CSI, 2014, Analysis Reference Manual for SAP 2000, ETABS, SAFE and CSiBrisge. Berkeley, California, USA: Computers \& Structures.

[20] Ciocci M.P. 2015, Structural Analysis of the Timber Structure of Ica Cathedral, Peru, MSc Thesis, Structural Analysis and Historical Constructions (SAHC) International Master Course, Guimarães, Portugal

[21] Poletti E., Vasconcelos G., Branco J.M., 2015, Experimental analysis of the cyclic response of traditional timber joints and their influence on the seismic capacity of timber frame structures, 3rd International Conference on Structural Health Assessment of Timber Structures, Wroclaw Poland, September 9-11, 2015 